\title{
The Use of Language Learning Apps as a Didactic Tool for EFL Vocabulary Building
}

\author{
Cesar A. Guaqueta ${ }^{1} \&$ Angela Yicely Castro-Garces ${ }^{1}$ \\ ${ }^{1}$ English and Spanish Department, Universidad del Tolima, Ibagué, Colombia \\ Correspondence: Angela Yicely Castro-Garces, English and Spanish Department, Universidad del Tolima, \\ Ibague, Colombia. E-mail: angelayicely@gmail.com
}

Received: October 19, $2017 \quad$ Accepted: January 10, $2018 \quad$ Online Published: January 11, 2018
$\begin{aligned} & \text { doi: 10.5539/elt.v11n2p61 } \\ & \text { URL: http://doi.org/10.5539/elt.v11n2p61 }\end{aligned}$

\begin{abstract}
This study explores the use of language learning apps as a didactic tool for vocabulary building in an English as a Foreign Language (EFL) context. It was developed through a mixed-methods approach, with a concurrent design in order to collect, analyze and validate qualitative and quantitative data. Although there was controversy on the use of technology in the classroom in the rural context where this study was developed, it advocated for practices that could go beyond the classroom boundaries and that were part of students' lives and social realities. The participants were 20 high school students and the intervention was during a six-month period. The data collection instruments included an initial diagnosis and a final development test, eight lessons and eight assessment sessions using language learning apps (Duolingo and Kahoot), eight entries to a research journal and a final survey. In the end, it was possible to provide evidence of the way technology and classroom practices can be allied to effectively foster vocabulary building.
\end{abstract}

Keywords: computer-mediated communication, teaching/learning strategies, improving classroom teaching, secondary education

\section{Introduction}

There has been much controversy and advances in the discussion of the benefits that the use of technology and online resources bring to foreign language teaching and learning. Different authors have agreed on the advantages of including technology for personal, social and educational purposes (Brown, 2014; Davis, 2006; Diaz, 2015; Jarvis \& Achilleos, 2013). Nevertheless, there are still many challenges to face when it comes to using this tool in the classroom. Teachers, on the one hand, often have to persuade their colleagues and supervisors of the academic purposes behind technology, and, on the other hand, face connectivity problems, overall in a rural setting as the one that was the context for this research project.

Notwithstanding, it is essential to consider that limited resources in our classroom make it challenging but not impossible to innovate our teaching practices; moreover, the latent need of students to find a purpose for learning the language and a good means to do so, trigger on teachers the possibility to rethink their practices, make them more appealing, and bridge that generational gap between them and their students. As Kumaravadivelu (2001) suggests, there is a need for language education that is context-sensitive, as we understand the linguistic, sociocultural and political particularities of our population. In this regard, one of the most remarkable aspects of this work is the particularity it embraces, as little research has been done in the rural area, even less taking technology as its main tool. "Language teachers can ill afford to ignore the sociocultural reality ... nor can they afford to separate the linguistic needs of learners from their social needs" (Kumaravadivelu, 2001, p. 544).

In effect, this study aimed at investigating the effects of using language learning apps (LLAs) as a didactic tool to foster vocabulary building in an EFL context. The context and population of this study gave us reasons to consider exploring new innovative ways in which a foreign language could be studied in a rural community. Students' little interest and low motivation to foreign language learning, reflected in little progress after years of instruction, and therefore low results in standardized exams, were the reasons which triggered this study. Taking advantage of a new computer lab with internet access brought to the school, our love for technology and students' interest in technological tools, such as cell phones and computers, we strived to find a means to bridge the gap between traditional classroom instruction and students' likes. 
The first step was to do a state-of-the-art of the different publications on the topic in question, in order to construct a solid theoretical framework. Although we found many studies that shed light upon the advances in research and publications in the field, there was nothing specifically mentioned about rural contexts; nevertheless, the publications found helped us nourish and reshape the direction of our research.

After that, we examined students' vocabulary skills, through an initial diagnosis test, which uncovered their real needs, and provided statistical evidence of their abilities, which could be compared and contrasted with the results obtained after the intervention. Once we noted their strengths and challenges, we implemented some vocabulary lessons through two LLAs (Duolingo and Kahoot) in order to help students learn, practice and assess their vocabulary development. Parallel to this process, we took notes of every event that occurred during each lesson and assessment session, through a research journal, in order to reflect upon students' process and learn by means of their experience, which is what Kumaravadivelu (2001) considers to be the role of the teacher researchers, "keeping one's eyes, ears and mind open in the classroom to see what works and what does not, ... and assessing what changes are necessary to make instruction achieve its desired goals" (p. 550).

In the end, based on the process developed by students, it was necessary to contrast findings revealed prior to the intervention with the final outcomes, in order to uncover potential progress on students' vocabulary development, as well as their own perception of the process lived. The findings presented a positive panorama on students' vocabulary building, as well as the development of a better attitude for language learning, which brought benefits to their current as well as future educational experience. As a result, this strategy had a positive influence in their learning in general, and in the development of vocabulary skills, as would be evidenced in the following chapters. Although thought for this specific group of students, it would certainly add to the technology and language education field as it presents strategies that can be used in other classroom settings to motivate and help students use technological resources with an educational purpose.

\section{Methodology}

\subsection{Research Design}

This study was developed through a mixed-methods approach with a concurrent design in order to collect, analyze, triangulate and validate qualitative and quantitative data to thoroughly approximate and illustrate the phenomenon under study. Due to the nature of this work, the concurrent design was adopted because it allows for the combination of both qualitative and quantitative approaches at the same level of hierarchy for a more systematic and reliable analysis.

Hernandez-Sampieri, Fernandez-Collado and Baptista-Lucio (2010) assert that the mixed-methods approach represents a set of systematic, empirical and critical processes of research, and imply the collection and analysis of quantitative and qualitative data, as well as its joint discussion and integration, to make inferences, product of all the information gathered (meta-inferences), and get a better understanding of the phenomenon under study.

\subsection{Context and Participants}

This study was conducted at La Voz de la Tierra School in Roncesvalles (Tolima) Colombia, with tenth graders. There were 13 girls and 7 boys from 14 to 17 years old. This is a rural school in Tolima whose children have to face several social problems such as violence and poverty. There are limited resources in the school, including no good access to ICTs, but also, no much material available for students to work outside the school. Students have two and a half hours of English instruction every week, but many of them do not like the language because they do not see a real use for it.

Students' little exposure and reluctance to learn English were the biggest challenges faced. Then, the goal was to find didactic alternatives that would encourage them to use the resources available to learn the language. Even though there was not good internet connection, students saw technological devices as their friends and wanted to share every minute of connectivity with them. All of them liked to interact with devices such as cellphones and desktop computers, so their ICT ability was good; therefore, this project was designed, taking students' strengths and needs into account, in order to foster vocabulary building to trigger their desire to learn the language.

\subsection{Instruments}

This project was carried out during a six-month period, using the following data collection instruments designed to facilitate the reaching of the research objective. There was an initial diagnosis test (IDT) and a final development test (FDT), eight lessons and eight assessment sessions with LLAs (Duolingo and Kahoot), eight entries to a research journal, based on every implementation, and a final survey. Confidentiality and anonymity were guaranteed during the research project. All group members assigned themselves nicknames to register to the LLAs, to which we assigned codes for data analysis; thus, $\mathrm{F}$ is the code for female participants, and $\mathrm{M}$ for 
male.

\subsubsection{Initial Diagnosis Test and Final Development Test}

This test was given to students at the beginning and at the end of the study. The purpose was to assess their level of vocabulary before the implementation with LLAs, in order to objectively measure their gains in this process. The test included 10 sections for students to identify vocabulary in context. Students were asked to answer two reading comprehension exercises, with multiple choice of vocabulary; match word and image; answer true/false; fill in the blanks; circle the correct word; and match word and definition. This test also served to raise students' awareness on the importance of building their vocabulary. The vocabulary included in the test was part of what would be learned through the apps; for that reason, it was useful to see how participants were at the beginning -which ones had more knowledge of the language and which ones needed to work harder to reach the goals set. Giving the same test at the end of the implementations facilitated the assessment of students' progress.

\subsubsection{Language Learning Apps -Duolingo and Kahoot}

Two English LLAs were selected according to a needs' analysis done with the students, prior to the interventions. The first one is Duolingo which provides a set of lessons to increase different language skills. It has two major components: grammar and vocabulary exercises and an interface to translate articles from the web.

Duolingo was used as an alternative to help students learn vocabulary of eight topics chosen at the beginning of the project. The use of this interface was a way to find didactic options which students could enjoy, as they expanded their vocabulary. The second one is called Kahoot which gives teachers the opportunity to design an instrument to assess students' performance during a lesson.

All students used Duolingo to practice the lessons during class time. As homework, they were asked to practice the lessons one more time and were given workshops to use the vocabulary learned. The week after each lesson studied with Duolingo, they were assessed through Kahoot. One of the strengths of this app is that every teacher can adapt already existing material to their own needs and purposes and give it a learning use, or design their own material based on the lessons studied. To play the game, the class needs internet access, a projector and a screen where students can visualize the activities. Kahoot was a good instrument for language learning gamification which encouraged students' intrinsic motivation and autonomy.

\section{Theoretical Framework}

Vocabulary building, technology and LLAs were the main theoretical constructs that supported this research study. The following chapter depicts the views of different authors who have added to this ever-growing field and also makes a connection between existing theory and this study.

\subsection{Vocabulary Building}

Among the language skills that any learner needs to be able to develop a linguistic competence, vocabulary is foremost a key component, which Easterbrook (2013) defines from two perspectives, the orthographical and the phonological. We find this distinction to be relevant in both English language -because its spelling widely differs from its pronunciation, and in a foreign language context -that presents students with a challenge for not having real-life opportunities to use it.

Additionally, Multicultural \& ESOL Program Services Education Department (2007), an organization dedicated to finding strategies for language learning, asserts that vocabulary development refers to the knowledge of stored information about the meanings and pronunciation of words necessary for communication. Although they recognize the many possibilities that language learners have for expanding their vocabulary, including television, the internet, newspapers, audio recordings, among others, they acknowledge the benefits of effective vocabulary instruction, which include: definitional and contextual information about a word, multiple exposures to a word in different contexts, and encouragement of students' active participation in their word learning. The different views of vocabulary learning have interaction, real-language use, teaching strategies and real purpose for using the new vocabulary learned as commonalities because besides having a goal in mind for learning, there should be moments for using the new knowledge for it to be meaningful.

For instance, Contreras, Charry and Castro (2016) explored the way the implementation of multimedia projects could help the speaking skill development in sixth graders, a population that was in need of didactic alternatives to boost their language learning skills. The authors recognize the notorious need for more vocabulary instruction at all levels to gain English proficiency, as well as the use of strategies that motivate, engage and foster long term and meaningful learning. Also, Devia and Garcia (2017) aimed at uncovering the impact of using podcasting, language learning strategies and collaborative work in the development of tenth graders' oral skills. 
This project exemplified the way students advanced in the development of the different components of the speaking skill, including vocabulary building, through the use of specific strategies, such as cognitive, metacognitive, and social language learning. Therefore, more evidence is presented on the importance of planned vocabulary teaching for the reaching of specific language goals.

Thus, our teaching strategies are to include a variety of experiences with vocabulary learning, encouraging students to learn by themselves, and as aimed at in this project, giving them tools for further language development, through the combination of technology and independent work, always making connections between existing and new knowledge. As a matter of fact, this is an invitation that we as teachers must accept in order to foster better long-term learning -context-related vocabulary teaching whose search for strategies occupies a primary position in course planning.

\subsection{Technology and Language Learning Apps}

The development of tools and strategies to have successful foreign language learning processes has been a continuous concern in our field. Since its birth, Information Technology (IT) has contributed to the exploration of new and innovative approaches to facilitate such processes. Attaran (2003) defined IT as the capacities that computers, software applications and telecommunications offer to organizations to deliver data, information, and knowledge. The definition as well as the ways IT is regarded have been evolving as it reaches and is more accessible to different populations. In any case, it is a means that, if properly used, can bring benefits to the language education field.

More recently, Clavijo, Quintana and Quintero (2011) studied the pedagogical potential of ICTs to promote new ways of collaborative learning through other learnings in the Colombian context and to bring students and teachers closer to the use of digital tools. They explored the educational role of technology and acknowledged the need to use students' reality to promote learning that is meaningful and contextualized. On the other hand, Izquierdo et al. (2017) developed a research study in public schools in Mexico to find out the connection between foreign language teaching and ICTs. They identified specific technological tools that teachers use in their classes, but also acknowledged that there are several hindrances related to the public school context.

Davis (2006) highlights the role of technology in different settings, influencing our lives and educational contexts. Thus, there is no way we can deny that the current and future context of language learning is to be mediated by computers, the internet and mobile devices. Nonetheless, the strategies used to integrate these in our classrooms will be the basis to have a successful learning experience.

In regards to teachers who are supportive of practices mediated by technology, Firat and Serpil (2017) did a comparative study of internet usage in different groups of teachers. They assert that teachers need to be internet literate so as to help their students gain internet competency. Adding to this, we consider that more than helping students gain competency, teachers and their classes are to be mediators between students and technology to help them make the best out of this tool. Likewise, different teacher researchers report their attempts to integrate Mobile learning or LLAs in their language classes. Golonka et al. (2014) developed a review of technology use in foreign language learning and teaching by examining 350 studies that include the use of newer technologies; they aimed at uncovering the types of technology and their effectiveness. Also, Hwang and Wang (2016) implemented a situated computer game in six graders in order to test the effectiveness of different guiding strategies in helping students acquire vocabulary. The results revealed that students had significantly better learning achievement with higher cognitive load and that it engaged them more than traditional classes.

Additionally, Chen (2016) developed a study that evaluates LLAs for second language learners, in order to know their benefits for adult learners. She studied eight LLAs including Duolingo, Shanbay Vocabulary, Speak English, among others, and described them based on content quality, pedagogical coherence, feedback, motivation, usability, customization and sharing, and she concluded that this review allows teachers to make informed decisions. This study is a good model to understand the need to do in depth research, adapt and customize the tools to be integrated in our classrooms in order to provide a meaningful learning experience for our students.

Terantino (2016) examined the effects of independent mobile assisted language learning (MALL) on vocabulary recalling and listening comprehension. He analyzed the characteristics of the apps preferred by the population studied and concluded that due to established goals and guidelines for playing as a means to provide language learning opportunities, students could have moderate gains in their skills development. Similarly, Almasri (2013) studied the use of mobile technology in education to uncover foreign language learners (FLL)'s perceptions regarding LLAs. She argues that although user interface designers and App programmers compete to develop the most effective LLAs, students should be able to decide the ones that work for them. Furthermore, Ionita and Asan (2016) recognize the advantage of using technology in our classes as an inherent part of the contemporary 
digital society where the digital natives have technology as part of their daily activities, given this enhances learning autonomy and helps develop language skills. They invite teachers and methodologists to consider the changes experienced in society that inevitably affect the ways we learn and teach.

The previous studies presented an overview of the state of the art of the use of technology for language learning. A few studies were found that address the specific issue of using LLAs to foster vocabulary development; nevertheless, the theory studied highly supports this research given it provided insights into what teachers are doing in different academic contexts. The advice given in many of the studies explored is the importance of seeing technology as an allied, and also the relevant role of the teacher as a channel between technology and students. It is therefore the teacher the one who plans and makes decisions that benefit his own learners, in student-centered classes where learners' active roles are evident. The drawbacks of technology are also to be considered because there should be a balance between the benefits it brings and the potential harms; that is why the teacher's role keeps being relevant no matter how advanced technology might be.

\section{Data Analysis and Results}

To examine the extent to which the use of LLAs fostered vocabulary building in EFL tenth graders, it was necessary to analyze all the events that took place in the different implementations; to observe students' reactions, limitations, constraints, misconceptions about the use of technology in the classroom, cellphones use regulation, as well as students' attitudes and level of commitment during the lessons. The data collected was then analyzed, and the most common findings grouped in categories to triangulate how all the instruments provided elements for the results obtained.

\subsection{Initial Diagnosis Test}

This initial test was essential to have a clear idea of the level of vocabulary students had at the beginning of the project. It was designed to explore students' strengths and weaknesses and allowed to identify specific areas that needed to be addressed during the intervention. Given vocabulary facilitates understanding and language use in general, students' limited vocabulary knowledge gave them much difficulty at the beginning to fill in the gaps or to find the best choice to complete a sentence. Table 1 illustrates the score obtained per participant in this test, within a scale of 100 .

Table 1. IDT

\begin{tabular}{llllll}
\hline Student & Score & Student & Score & Student & Score \\
\hline F1 & 32 & F8 & 24 & M2 & 31 \\
F2 & 36 & F9 & 42 & M3 & 16 \\
F3 & 58 & F10 & 29 & M4 & 47 \\
F4 & 45 & F11 & 34 & M5 & 26 \\
F5 & 46 & F12 & 28 & M6 & 48 \\
F6 & 18 & F13 & 65 & M7 & 34 \\
F7 & 22 & M1 & 53 & & \\
\hline
\end{tabular}

Group average: 36.7

The average score for the group of 20 students was 36.7 out of 100 , which means that, as a group, they did not get the minimum passing grade, had they been evaluated taking into account school guidelines, which require students to score at least 60 points to pass.

When grouping students by the score obtained, it could be evidenced that only one student scored above 60 , and seven students 30 or below. Based on the guidelines established by the National Ministry of Education, tenth graders should have an A2 level in the Common European Framework of Reference, going to B1, which is required by the time they finish high school. The low scores obtained by the majority of students reveal that they are far from reaching those objectives, which would also affect their standardized test results.

Among the different categories evaluated, students had more strengths in vocabulary related to familiar entities, such as personal information, numbers and family members. Their weaknesses included vocabulary related to food, travelling and clothing. The previous data confirmed the alarming situation lived not only in rural schools, 
but also in many other schools nationwide, in which the English learning process has not reached the expected goals; therefore, the need to continue searching for better alternatives to remediate the current panorama is latent.

\subsection{Lessons, Assessment Sessions and Research Journal}

Following is an analysis of the data collected based on the lessons studied through Duolingo, the assessment sessions done through Kahoot and the research journal entries. The eight moments experienced will be described in order to create an understanding of the way the intervention was developed. It was deemed necessary to create a parallel among these three instruments (Duolingo, Kahoot, and Research Journal), as the three were the components of each one of the eight interventions, as follows: First the vocabulary was presented through Duolingo, the week after students were assessed through Kahoot and during both the lesson and the assessment notes were taken to analyze the experience. The eight topics studied were: (1) greetings, (2) travelling, (3) clothing, (4) school, (5) animals, (6) friends, (7) food, and (8) the human body.

During the first lesson, students were introduced to the two LLAs and to the generalities of the topics that would be studied during the following weeks. There was a mixture of feelings of excitement, fear and anxiety, since for most of them English was not an easy language to learn, nor their favorite school subject. Once they signed up and began to practice with the two LLAs, the panorama changed for the better, as they started to realize the positive role that technology could have in their learning process. They started to regard their cell phones as learning friends, and not only as a tool that could be confiscated if they misused it. They now had the opportunity to use them in class and had to portray a sense of responsibility, which although more challenging at the beginning, was adopted afterwards.

Greetings was a topic familiar to them, nonetheless, the review helped them better the pronunciation of some words such as night, please and the $[\Theta]$ in thanks, as well as to remember some other such as speak and welcome. The results of the first assessment made some students uneasy, but gave confidence to most of them. They were all motivated during the test and eager to see their final score. A score of 75.95 as group average was satisfying, but there was still lots of work to do with students. Only M3 scored below 60 and three students above 90 points. The sixteen remaining had an average score, which was good for their first assessment.

During the second intervention, 17 students scored above 60 points while only three were below. The topic presented a great challenge for many students because of words such as newspaper and luggage. No student had more than 90 points and the total average lowered to 66.25; the lowest of all interventions. We knew that more needed to be done in order to continue encouraging students to review at home and to take advantage of time at school to do so as well.

Subsequently, we designed an additional lesson with the vocabulary studied for students to practice using their computers. It was rewarding to hear them using expressions such as 'que vacano [how nice], que chevere [how cool], me gusta esto [I like this],' as this was a signal of them getting more engaged. Also remarkable was the fact that they concentrated on the task and did not attempt to open Facebook or Youtube during their work that day.

Clothing, which was the topic of the third intervention was one of the most challenging during the IDT, therefore, additional practice was provided for students in order to facilitate the learning of this vocabulary. In fact, the results of five students were below 60, and only one them above 90. Although not that much, students were advancing little by little. Students such as $M 3$ kept being a concern during the process because although he attended every class his progress was not as evident as that of other students. We talked to students who had low results, offering them more support, but for most of them English was still a big challenge, and additionally they did not dedicate enough time to practice it. They promised to work harder in order to continue improving.

Given the assessment sessions were competitive, students were doing their job, but also reporting other students who tried to cheat using translators. We raised awareness on the importance of self-regulating their learning and reviewing at home. This situation bettered in the following interventions. Nevertheless, there were also positive situations of students trying to collaborate with peers during the lessons. They asked for permission to go help others saying 'Can I go to X and help? I see she is lost, or 'I want to help those partners who have difficulties.'

The unit on school was appealing to all students as they could easily appropriate the terms. We put into practice the knowledge gained, then when assessment time came they were all excited and prepared. The group average of 80.15 was the highest of all interventions, which encouraged students much more. No student had below 60 points and four of them had over 90, highlighting $M 7$ who had very high scores in all interventions and this time had a perfect score of 100 . The vocabulary learned this time gave students tools to continue using words such as pen, learn, study, class, school and idea in other classes. Some of them reported their like for Duolingo saying 
'Duolingo is a good tool to practice English when we are doing nothing,' and 'I like this app because I practice and it grades me.'

The topic of intervention five was one students are familiar with because of their context. Thus, talking about vocabulary related to animals and their environment was a good way of localizing knowledge or having 'context-sensitive language learning' (Kumaravadivelu, 2001). Only one student scored below 60, while five scored above 90. It was great to see students enjoying the lesson and asking additional questions to expand their vocabulary. They wanted to learn not only the names of the animals, but also vocabulary related to agricultural processes, such as milking cows, dairy products and coffee growing. This was an opportunity to go beyond the vocabulary suggested in Duolingo and work with students' goals, needs and interests in mind.

During lesson six students work was not outstanding. The group scored a total of 77.55, which was just above average compared to the different interventions. Three students were below 60, while other three above 90 . Learning about days of the week, dating and going out with friends did not awaken any special interest in students. This was probably not a relevant aspect in their lives and context, nonetheless, they worked and kept committed to the practice in the classroom and at home.

The vocabulary presented in lesson seven was expanded with different products that students have in their farms. They wanted to learn words such as strawberries, beef and potatoes, which were not included in the Duolingo list. They gave examples of what they usually have for every meal and practiced the numbers and times studied in previous units. They enjoyed the assessment session as much as the lesson, and even though five of them obtained results below 60, they did not feel discouraged because they felt they had learned a lot. Only $F 13$ and $M 7$ obtained scores above 90, but it was because of their extra dedication and commitment displayed since the beginning of the interventions.

This last intervention about the human body showed students' mastery of the process, good work alone the lesson and great performance in the assessment session. Even though the group score was below average compared to all interventions, students learned many new words and had a better attitude toward the language, which gave them tools to study and improve on their own after the interventions. Five students scored below 60 and three of them above 90. Our constant observation and reflection of the process allowed us to notice positive changes in students, as they enjoyed the classes more and were not worried about being assessed. They saw assessment as a natural part of the learning process and felt more motivated to improve because of the additional practice they could have with the use of their cell phones or computers at school.

\subsection{Final Development Test}

The final development test was a way to remember our starting point. Students faced it with confidence and no fears. The different lessons studied and assessed boosted their vocabulary progressively as can be observed in Table 2 that provides a description of all assessment sessions (AAS). Students started with an average of 36.7 in the IDT, then bounced back and forth in the study of different topics.

Some lessons such as personal information, school items and animals were learned at a faster pace, while other such as travelling, the human body and clothing gave them more difficulty. Additionally, topics such as food, animals and school provided more real interaction as they could be easily experienced in their own lives.

Table 2. AAS

\begin{tabular}{ll}
\hline Assessment sessions & \\
IDT & 36,7 \\
\hline Assessment 1 & 75.95 \\
Assessment 2 & 66.25 \\
Assessment 3 & 68.25 \\
Assessment 4 & 80.15 \\
Assessment 5 & 79.7 \\
Assessment 6 & 77.55 \\
Assessment 7 & 70.6 \\
Assessment 8 & 72.65 \\
\hline
\end{tabular}


Table 3 presents a detailed description of the scores obtained by students during the FDT. Compared to the IDT, all students gained more vocabulary as expected. The experience was successful in terms of vocabulary learning, language attitude, confidence, and use of technological resources available.

Table 3. FDT

\begin{tabular}{llllll}
\hline Student & Score & Student & Score & Student & Score \\
\hline F1 & 62 & F8 & 59 & M2 & 65 \\
F2 & 80 & F9 & 72 & M3 & 32 \\
F3 & 89 & F10 & 82 & M4 & 84 \\
F4 & 67 & F11 & 76 & M5 & 63 \\
F5 & 78 & F12 & 80 & M6 & 86 \\
F6 & 65 & F13 & 92 & M7 & 94 \\
F7 & 72 & M1 & 71 & & \\
\hline
\end{tabular}

Group average: 73.45

The results depicted in table 3 illustrate how only two students had scores below $60 ; F 8$ had a score of $59-25$ points above her IDT, and M3 a score of $32-16$ points above his IDT. It is worth highlighting that eight students were above 80 points, including two who were above 90 points. F13 scored $92-37$ above her IDT, and $M 7$ who usually had a leading position in all the interventions scored $94-64$ points above his IDT. M7 was a great example for his partners because he excelled from an IDT of 34 points to an FDT of 94. The outcomes presented in the FDT allowed us to infer that the means adopted to help students improve their vocabulary was successful for most of them who took this as a learning opportunity.

\subsection{Final Survey}

At the end of all interventions, after noticing that students' attitude toward the language was better and knowing how much they had expanded their vocabulary, a survey was administered in order to have a better understanding of their perceptions toward LLAs for English learning. They were asked three open-ended questions, in which they could freely express their experiences lived during the project. Students' answers were categorized by the most common terms expressed; thus, five categories were derived from question one, five from question two, and four from question three.

Table 4. Technology for learning

Question 1: Do you think the use of technology contributes to your learning? How?

Easies the learning process

Helps self correction

Helps get knowledge

Improves my English

Classes are more active

Table 5. LLAs for learning

Question 2: Describe your experience with the use of Duolingo and Kahoot as English learning strategies

Good strategy, playful and didactic

Duolingo helped me to get prepared for kahoot 
Made my English learning process easy

Duolingo is organized and clear

They helped me to acquire vocabulary

Table 6. Technology for a language experience

Question 3: How has the use of technology inside and outside the classroom changed your English language learning experience?

Change the English class routine

More didactic activities

Learn more English

Entertainment and concentration

The categories portrayed in the different tables reveal the positive perception that students had toward LLAs to improve their English, as they acknowledged the multiple benefits derived from this project. No drawbacks were expressed or observed during the intervention. Among the most remarkable aspects mentioned was the use of more didactic activities, having fun while learning and expanding their vocabulary. In sum, this project gave students the possibility to see the positive side of technology to improve their English now and to gain strategies for future learning on their own.

\subsection{Common Categories of Analysis (CCA)}

The six data collection instruments used were key elements to reach the objective set in this research study. The IDT and FCT allowed the identification of vocabulary knowledge at the beginning of the project in order to create strategies to gain more vocabulary, and also to uncover the new knowledge acquired at the end of all the interventions. Some of the common problems identified were vocabulary related to food, travelling and clothing, while most students did better in vocabulary related to personal information, numbers and family members. The analysis suggests that students' basic knowledge allowed them to identify some vocabulary which had been previously worked in other classes, nevertheless, the other word categories needed more time to be appropriated.

Moreover, Duolingo and Kahoot were paired up as they provided vocabulary practice and gave opportunities for students to evaluate their knowledge and identify the need to continue improving. Students' desire to participate in the project was beneficial, however, they had a lot to learn in the process. Once they understood how it all worked, they became good at practicing the lessons and competing in the tests. Some of the common aspects derived from these two instruments were students' interest in both the lessons and the assessment sessions, and students' improvement during and after them. One major gain was the fact that students improved not only for the moment, but also for life as they learned new strategies that will help them go on their own.

At the same time, the Research Journal and Students Survey were moments of reflection that spinned around the vocabulary practice and assessment as a way to understand and improve the process and systematize the benefits derived from it. Some of the most common occurrences in these two instruments were:

- Students were fearful and lack of confidence at the beginning of the project.

- English was not their favorite subject and they considered it a difficult language to be learned.

- Students use of technology was limited to opening their Facebook account, YouTube content and other non-academic activities.

- They did not know about the existence of LLAs.

- Their behavior changed as they understood LLAs' benefits and level of enjoyment.

- They gained confidence and assurance that they were improving every day.

- The process of feedback provided by the LLAs and by the teachers gave students a sense of relief and guaranteed a continuous learning process.

- Students wanted to collaborate with others to help them reach the goals set.

- Students visited the school in the afternoon to access Wi-Fi and continue practicing. 
- $\quad$ Parents became involved in the projects; although most parents are not usually involved in their children's academic matters, this project made them want to help them as they saw kids practicing at home and coming to school in the afternoon.

- $\quad$ There was meaningful learning derived as students found the process to be attractive and related to their own lives.

- Students better attitude is expected to help them develop other skills, such as Reading comprehension, which will also help them better their results in standardized exams.

\section{Conclusions}

Because today's classroom represents increasing diversity among students, a teacher has to accommodate to this range of differences -developmental, motivation to learn and achievement (Larrivee \& Cooper, 2006). These authors' call for reflection is what every practitioner should aim at; reflecting upon our practices makes us be in a continuous process of inquiry that allows us to make informed decisions based on our students' needs and realities.

In this way, this project was born from a needs' analysis done with a student population, in order to uncover their feelings, attitudes and likes toward English; done in such a way because changes are to be implemented with teachers' experience and expertise in mind, but always considering the target population that is to benefit from them. This study was developed in a community whose social problems interfere with the desire for learning, so the biggest challenge was to accommodate teaching practices to the specificities of the group, in an era where there are no magic recipes to teach, where teachers have general guidelines, but are to be tailors of their own classrooms, and where no student is to be left behind.

It was essential to consider Kumaravadivelu's (2001) proposal of having a pedagogy of particularity (relevant and sensitive to a particular group), practicality (bridging the gap between theory and practice) and possibility (social practices to empower students). With all of this in mind and the decision of helping students improve and gain tools that would accompany them once the project was over, we anticipated that the use of technology as a didactic tool would foster vocabulary building. Although we knew the challenges to be faced, such as connectivity problems and students' reluctance to practice the language, we also knew that using appropriate strategies would help us have great results.

One aspect we considered essential to achieve was life-long meaningful learning; for that reason, vocabulary development was the starting point for students to enjoy English learning as they improved their language skills and gained strategies to work on their own in the future. At the end, students' perceptions were highly evidenced through the final survey. Their answers provided positive feedback for the project and no negative reactions were evidenced. All students agreed that their participation in this process was beneficial for their current and future learning of English. They also manifested to be interested in studying other topics using LLAs because this was a much more dynamic and fun way to learn. They agreed that they now see English as a subject that is more integrated to their lives because they can study topics they like in this language.

In addition to helping students develop their vocabulary, a side effect of the project was to see them motivated to read more in English because they could understand better. This is positive as standardized exams have presented a big challenge to students of this school whose results are below the national average in English and other subjects. Therefore, as further research we plan to design and develop a project that helps students improve their reading skill. Vocabulary learning was the starting point, which will be more widely developed if they continue using the strategies learned.

In sum, with limited resources, challenges ahead, reluctant students, but a potential for improvement, this project was a good opportunity to take advantage of the resources at hand to help students improve their vocabulary. The results were all positive and encouraging to continue bettering our teaching practices.

\section{References}

Almasri, R. (2013). The use of mobile technology in education by international students in United States universities: Perceptions regarding mobile applications for English language learning. Ann Arbor: ProQuest.

Attaran, M. (2003). Information technology and business-process redesign. Business Process Management Journal, 9(4), 440-458. https://doi.org/10.1108/14637150310484508

Brown, J. (2014). Teachers' stances on cell phones in the ESL classroom: Toward a "theoretical" framework. TESL Canada Journal, 31(2), 67-78. https://doi.org/10.18806/tesl.v31i2.1177 
Chen, X. (2016). Evaluating language learning apps for second language learners. Journal of Educational Technology Development and Exchange, 9(2), 39-51. https://doi.org/10.18785/jetde.0902.03

Clavijo, A., Quintana, A., \& Quintero, L. M. (2011). Enseñanza del Inglés y medios digitales: nuevos retos y posibilidades para la Escuela. Bogota: Editorial UD.

Contreras, L., Charry, S., \& Castro, A. (2016). Speaking skill development through the implementation of multimedia projects. Gist: Education and Learning Research Journal, 12(1), 8-28.

Davis, R. (2006). Utopia or chaos? The impact of technology on language teaching. The internet TESL Journal, 12(11).

Devia, M., \& Garcia, A. (2017). Oral skills development through the use of language learning strategies, podcasting and collaborative work. Gist Education and Learning Research Journal, 14(1), 32-48.

Diaz, I. (2015). Training in metacognitive strategies for students' vocabulary improvement by using learning journals. Profile, 17(1), 87-102. https://doi.org/10.15446/profile.v17n1.41632

Easterbrook, R. M. (2013). The process of vocabulary learning: vocabulary learning strategies and beliefs about language and language learning (Unpublished doctoral thesis), University of Canberra, Australia.

Firat, M., \& Serpil, H. (2017). Comparing the internet usage of pre-service language teachers with teachers of other subjects: Distance learning vs. on-campus learning. Profile, 19(1), 55-72. https://doi.org/10.15446/profile.v19n1.54184

Golonka, E., Bowles, A., Frank, V., Richardson, D., \& Freinek, S. (2014). Technologies for foreign language learning: a review of technology types and their effectiveness. Computer Assisted Language Learning, 27(1), 70-105. https://doi.org/10.1080/09588221.2012.700315

Hernandez-Sampieri, R., Fernandez-Collado, C., \& Baptista-Lucio, P. (2010). Metodología de la Investigación (5ta. Ed.). Ciudad de Mexico: McGraw-Hill.

Hwang, G. J., \& Wang, S. Y. (2016). Single loop or double loop learning: English vocabulary learning performance and behavior of students in situated computer games with different guiding strategies. Computers \& Education, 102, 88-201. https://doi.org/10.1016/j.compedu.2016.07.005

Ionita, M., \& Asan, D. (2016). Learning foreign languages by using mobile apps within integrated educational platforms. Proceedings of the $12^{\text {th }}$ International Scientific Conference eLearning and Software for Education (pp. 115-120). Bucharest, Romania: "Carol I" National Defence University.

Izquierdo, J., De la Cruz Villegas, V., Aquino Zuñiga, S., Sandoval Caraveo, M., \& García Martinez, V. (2017). La enseñanza de la lenguas extranjeras y el empleo de las TIC en las escuelas secundarias públicas. Comunicar, 50(25), 33-41. https://doi.org/10.3916/C50-2017-03

Jarvis, H., \& Achilleos, M. (2013). From computer assisted language learning (CALL) to mobile assisted language use (MALU). TESL-EJ, 16(4), 1-18.

Kumaravadivelu, B. (2001). Toward a post-method pedagogy. TESOL Quarterly, 35(4), 537-560. https://doi.org/10.2307/3588427

Multicultural \& ESOL Program Services Education Department. (2007). Vocabulary. Author, 25-37.

Terantino, J. (2016). Examining the effects of independent MALL on vocabulary recall and listening comprehension: An exploratory case study of preschool children. Calico Journal, 33(2), 260-277.

\section{Copyrights}

Copyright for this article is retained by the author(s), with first publication rights granted to the journal.

This is an open-access article distributed under the terms and conditions of the Creative Commons Attribution license (http://creativecommons.org/licenses/by/4.0/). 